\title{
Anemia in Mexican women: A public health problem
}

Teresa Shamah-Levy, MSc, ${ }^{(1)}$ Salvador Villalpando, MD, Sc. Dr, ${ }^{(1)}$ Juan A. Rivera, MS, PhD, (1) Fabiola M ejía-Rodríguez, BSC, ${ }^{(1)} M$ artha Camacho-C isneros, BSC, ${ }^{(1)}$ Eric A Monterrubio, BSc., ${ }^{(1)}$

\section{Shamah-LevyT, Villalpando S, Rivera JA, Mejía-Rodríguez F, Camacho-Cisneros M, Monterrubio EA. Anemia in Mexican women:A public health problem. Salud Publica Mex 2003:45 suppl 4:S499-S507. \\ The English version of this paper is available too at: http://www.insp.mx/salud/index.html}

\begin{abstract}
A bstract
Objective.The purpose of this study is to quantify the prevalence and distribution of anemia among women of childbearing age (12 to 49 years) participating in the 1999 N ational N utrition Survey (N N S-1999). Material and Methods. The survey had a probabilistic design and was representative at the national level, of urban and rural areas and four regions: N orth, South, Center, and Mexico City. Hemoglobin concentration was determined in capillary blood samples using a portable photometer (H emoCue), in 17194 women, 697 of whom were pregnant. Results The overall prevalence of anemia was $27.8 \%$ in pregnant women and $20.8 \%$ in non-pregnant wo men. Higher prevalences were observed in rural as compared to urban areas, both in pregnant $(28.0 \%$ vs $27.7 \%)$ and non-pregnant $(22.6 \%$ vs $20.0 \%)$ women, but the differences were not statistically significant $(p>0.05)$.W omen in the South had the greatest prevalence $(23.2 \%)$, followed by those in the N orth $(20.9 \%)$, Center $(20.6 \%)$, and Mexico City (16.4\%). N on-pregnant indigenous women had a prevalence of $24.8 \%$, while in-non-indigenous wo men the prevalence was $20.4 \%$. Conclusions A nemia in women of childbearing age is a growing public health problem that justifies the implementation of interventions for its prevention and control. The English version of this paper is available too at:http://www.insp.mx/salud/index.html
\end{abstract}

Key words: nutrition surveys; nemia; pregnant women; hemocue; hemoglo bin; Mexico

\begin{abstract}
Shamah-LevyT,Villalpando S, Rivera JA,
Mejía-Rodríguez F, Camacho-Cisneros M, Monterrubio EA.

Anemia en mujeres mexicanas: un problema de salud pública. Salud Publica Mex 2003;45 supl 4:S499-S507.

El texto completo en inglés de este artículo también está disponible en: http://www.insp.mx/salud/index.html
\end{abstract}

\section{Resumen}

Objetivo. Cuantificar la prevalencia y distribución de anemia de las mujeres en edad fértil (12 a 49 años de edad) captadas en la Encuesta N acio nal de N utrición 1999 (EN N 99). La Encuesta tuvo un diseño probabilístico y es representativa del ámbito nacional mexicano, de zonas urbanas y rurales y de cuatro regiones: norte, centro, C iudad de México y sur. Material y métodos La concentración de hemoglobina se determinó en sangre capilar mediante un fotómetro portátil (HemoCue) en 17194 mujeres, de las cuales 697 estaban embarazadas. Resultados La prevalencia de anemia en el ámbito nacional fue de $27.8 \%$ para mujeres embarazadas y $20.8 \%$ para no embarazadas. Se encontró una mayor prevalencia en zonas rurales que en urbanas, tanto en mujeres embarazadas $(28.0 \%$ vs $27.7 \%$ ) como en no embarazadas (22.6\% vs $20.0 \%$ ) pero las diferencias no fueron estadísticamente significativas ( $p>0.05)$. La región sur presentó la mayor prevalencia de anemia ( $23.2 \%)$, seguida de la región norte (20.9\%), la centro (20.6\%) y la Ciudad de México (16.4\%). Las mujeres no embarazadas indígenas presentaron una prevalencia de anemia de $24.8 \%$, mientras que en las no indígenas fue de $20.4 \%$, no siendo esta diferencia estadísticamente significativa. Conclusiones. La anemia en mujeres en edad fértil es un problema de salud pública que justifica la implantación de programas de prevención y control. El texto completo en inglés de este artículo también está disponible en: http://www.insp.mx/salud/index.html

Palabras clave: encuestas nutricionales; anemia; mujeres embarazadas; hemocue; hemoglobina; México

(1) Centro de Investigación en N utrición y Salud, Instituto Nacional de Salud Pública, Cuernavaca, Morelos, México.

Received on:A ugust 20,2002 - Accepted on: 0 ctober 14,2003

Address reprint requests to: Mtra. Teresa Shamah Levy, D epartamento de Vigilancia de la N utrición, Instituto N acional de Salud Pública, Avenida Universidad 655, colonia Santa María A huacatitlán 62508 Cuernavaca, Morelos, México.

E-mail: tshamah@ correo.insp.mx 
A nemia is the most frequent nutritiona-related disease worldwide, affecting half of children and pregnant women and between 20 and $25 \%$ of non-pregnant women in developing countries. ${ }^{1}$ Both nutritional and non-nutritional factors may cause anemia. The most common nutritional cause is iron deficiency. Other nutritional causes are deficiencies of vitamin $B_{12}$, folic acid, and vitamin A. ${ }^{2-4}$ Among the non-nutritional causes of anemia are intestinal parasitic infections such as uncinariasis and trichinosis. ${ }^{5-8}$ Other causes include hemodilution during pregnancy, concurrent acute and chronic infections, and menstrual bleeding. ${ }^{9,10}$ Iron deficiency also has deleterious effects on the immune response, exercise endurance, cognitive ability, and psychosocial development. ${ }^{11,12}$

The extent to which anemia affects the health of mothers and of their newborns is not completely established, but some studies suggest that anemia during pregnancy has adverse effects on both the mother and the fetus. ${ }^{13,14}$ Moreover, severe anemia greatly increases the risk of maternal death. ${ }^{10,14}$ Insufficient maternal iron stores are reflected in low iron stores in the newborn, leading to increased risk of iron deficiency in the first months of life. Iron deficiency may also have long-term consequences on the health of both mother and child. For example, iron deficiency anemia is associated with birth weight and pre-term birth.

The most recent information on the extent and distribution of anemia in Mexico was reported in the 1988 National Nutrition Survey. ${ }^{15}$ The present study was designed to quantify the prevalence and describe the distribution of anemia in women aged 12 to 49 years, at the national level, by urban and rural areas and by region, and to assess the trend in anemia prevalence comparing the findings from this study to those of the 1988 National Nutrition Survey.

\section{Material and Methods}

\section{Sample design and procedures}

Data for this analysis were obtained from the 1999 National Nutrition Survey (NNS-1999). ${ }^{16}$ A general description of the NNS-1999 methods is included elsewhere in this issue. In summary, the NNS-1999 assembled a probabilistic sample of 21503 households, representative at the national level, stratified by urban (pop $\geq 2500$ ) and rural residency (population $<2500$ ), and by four geographic regions of Mexico: (North,
Center, Mexico City, and South). ${ }^{*}$ Families were selected according to a sampling frame developed by INEGI (acronym from its Spanish name: Mexican National Institute of Statistics, Geography and Information).

Sampling procedure for NNS-1999 followed a multistage, stratified, cluster design. The survey included diverse data collection strategies for different age groups. In each household, data were collected from all children $<5$ years of age and school-age children (5-11 years), but only from one woman aged 1249 years.

Only one woman between the ages of 12 and 49 was selected from those living in a given household. Data obtained from 18312 women aged between 12 and 49 years were retrieved for this analysis, including those subjects having information available on hemoglobin concentrations, physiological status (pregnant, lactating, non-pregnant non-lactating), ethnic background, socioeconomic status (SES), maternal parity, education, employment, and maternal literacy. For this analysis, indigenous background of a family was operationally defined as at least one woman 12-49 years of age who spoke a native language. The socioeconomic level was graded using principal components analysis. Selected variables were flooring material, availability of running water, ownership of household electrical appliances (washing machine, refrigerator, television, radio, and stove). This index explained $51.6 \%$ of the generalized variance of the set of variables included. The distribution of this index was divided into tertiles to classify SES into high, medium, and low strata. Parity was stratified into three categories: women with less than three children, three to five children, and more than five children. Maternal education was stratified into five categories: no education, primary, secondary, high school or equivalent, and completed college education. Employment status was stratified into three categories: paid job, student, and housewife. Maternal literacy was divided into two cat-

\footnotetext{
* North (Baja California, Baja California Sur, Coahuila, Chihuahua, Durango, Nuevo León, Sonora and Tamaulipas), Center (Aguascalientes, Colima, Guanajuato, Jalisco, México (excludes urbanised counties and localities adjacent to Mexico City), Michoacán, Morelos, Nayarit, Querétaro, San Luis Potosí, Sinaloa, Zacatecas), Mexico City (includes Federal District and urbanised counties from the state of México). South (Campeche, Chiapas, Guerrero, Hidalgo, Oaxaca, Puebla, Quintana Roo, Tabasco, Tlaxcala, Veracruz, Yucatán)
} 
egories: literate was defined as the ability to read or write a message, and illiterate otherwise. Some cases were excluded from the analysis when information on hemoglobin concentration or physiological status was not available.

Informed consent letters were obtained from women prior to their participation in the survey. The NNS1999 protocol was approved by the Ethics Committee of the National Health Public Institute, Mexico.

\section{Definition of anemia}

Anemia was defined as the concentration of hemoglobin at sea level $<12.0 \mathrm{~g} / \mathrm{dl}$ in non-pregnant women and $<11.0 \mathrm{~g} / \mathrm{dl}$ in pregnant women. ${ }^{17}$ For localities $>1000$ $\mathrm{m}$ above sea level, hemoglobin values were adjusted according to the method proposed by Cohen and Hass. ${ }^{18}$ These authors derived a hemoglobin-altitude curve from previously published data of mean hemoglobin concentrations of non-anemic women of childbearing age at various altitudes. They assumed that the mean hemoglobin concentration of the iron-sufficient population at sea level was not significantly different from the mean up to 1000 meters above the sea level. Four data points were used from 1000 to 4800 meters.

The curve which best fitted the hemoglobin-altitude for non-anemic women of childbearing age was:

$$
\begin{gathered}
\text { Hemoglobin }(\mathrm{g} / \mathrm{l})=120+16.3 \times\left[\exp ^{(0.00338 \times \text { (altitude }-1000))}\right] \\
\left(\mathrm{R}^{2}=0.995, p<.05\right)
\end{gathered}
$$

The assumed coefficient of variation of 0.061 of the adjusted estimated hemoglobin values is then used to calculate the hemoglobin cutoff point at the 2.5 percentile of normal distribution. Using the results from the mean-hemoglobin equation above, the hemoglobin cutoff to estimate anemia is calculated as follows:

$$
\mathrm{Hb} \text { cutoff }=\text { Mean } \mathrm{Hb}-[(0.061 \times \text { Mean } \mathrm{Hb}) \times 1.96]
$$

This model can be used to estimate the prevalence of iron-deficiency anemia in women of childbearing age, including the period of pregnancy, at altitudes up to $4800 \mathrm{~m}$.

Data on altitude of our study communities were obtained from the INEGI database. ${ }^{19}$

\section{Hemoglobin measurements}

Blood hemoglobin was determined in a sample of capillary blood obtained by fingerprick, using the second drop of blood obtained and measured by a portable photometer (HemoCue, Angelholm, Sweden). This test is based on a reaction occurring in a plastic cuvette containing a dry reactant (sodium deoxycholate, sodium nitrite, and sodium azide). This reaction converts hemoglobin into azide methemoglobin, which is measured at a wavelength of $565 \mathrm{~nm}$ in the portable photometer. The photometer is previously calibrated with a reference cuvette equipped with a red filter, calibrated against the international hemoglobin standard ${ }^{20}$ as recommended by the International Committee of Standardization in Hematology.

There was one photometer for each of the 21 field teams. Photometers were calibrated twice each week during fieldwork, recording the readings of the control cuvette at the beginning and end of each day. If the variation was $>0.3 \mathrm{~g} / \mathrm{dl}$, the photometer was serviced. The intra-observer variability was assessed by duplicate measurements of a blood sample, once every 20 subjects screened. There were 582 duplicate human blood measurements and 273 measurements of the reference cuvette available for variability analysis per team. The average difference between duplicates was $0.03 \pm 0.99 \mathrm{~g} / \mathrm{dl}, p=0.36$ for human blood and $-0.024 \pm 0.36 \mathrm{~g} / \mathrm{dl}, p=-0.27$ for the duplicates of the reference cuvette.

Values of hemoglobin $<4.5 \mathrm{~g} / \mathrm{dl}$ and $>18.5 \mathrm{~g} / \mathrm{dl}$ were considered as outliers and excluded from the analysis. Women with hemoglobin values $<9 \mathrm{~g} / \mathrm{dl}$ were treated with ferrous sulfate tablets, and excluded from the analysis. The final sample size for analysis was 16 497 women, 697 of whom were pregnant at the time of the interview.

For analysis purposes, women were categorized as pregnant or non-pregnant. Since the distribution of the hemoglobin data was not different between nonpregnant, non-lactating and lactating women, these two were merged into the category of non-pregnant women.

\section{Statistical analysis}

Descriptive data analysis are presented as prevalence of anemia and mean hemoglobin concentrations with their 95\% confidence intervals (CI). The probability of being anemic was evaluated through a logistic regression model for complex surveys. The independent variables in the model were those that have been documented to be associated with anemia: indigenous background, socioeconomic status, maternal education, employment status and maternal literacy. ${ }^{21-26}$ Expansion factors were calculated based on the characteristics of the national population in 1995.

Regression models for the analysis of potential predictors of anemia were constructed with data from non-pregnant women only. 
Data entery was done using a Clipper-based program using formats that included range and contingency validation checks (V. 5.01, 1999; Nantucket ${ }^{\text {TM }}$ Corporation, San Francisco, CA, USA). A descriptive analysis was run in SPSS for Windows (v. 10, 1999; SPSS Inc, Chicago, IL, USA). Regression models were adjusted using Stata statistical software (v. 7.0, 2001; Stata Corp., College Station, TX, USA).

\section{Results}

The final sample for the present analysis was composed of 17194 registries of the original NNS-1999 sample due to the exclusion of 1119 observations (6.1\%), either because they were incomplete or outliers. The age distribution and the socioeconomic characteristics of the excluded cases were not different from those of the final sample, either by region, or by urban and rural distribution.

At the national level, the mean hemoglobin concentration for pregnant women was $11.9 \mathrm{~g} / \mathrm{dl}$ (median $=12.0 \mathrm{~g} / \mathrm{dl}$ ) and non pregnant women was $13.1 \mathrm{~g} / \mathrm{dl}$ (median=13.2 g/dl). The mean hemoglobin values for urban and rural pregnant women were identical and were slightly lower in rural areas for non-pregnant women. Mean hemoglobin values were higher in Mexico City than in other regions for both pregnant and non-pregnant women. The lowest mean values for pregnant and non-pregnant women were found in the North and South (Table I).

The overall prevalence of anemia was $27.8 \%$ (95\% CI 23.7, 31.8\%) for pregnant women and 20.8\% $(95 \%$ CI $19.9,21.7 \%)$ for non-pregnant women. The prevalence of anemia in pregnant urban women was not different from that of rural women (27.7 vs. 28.0\%). Non-pregnant rural women had a greater prevalence of anemia than their urban counterparts (22.6 vs. 20.2\%). (Table II).

Due to small sample sizes, regional prevalences for rural areas are not presented in Mexico City for either pregnant and non-pregnant women nor in the north for pregnant women.

In urban and rural non-pregnant women, the highest prevalence of anemia was found in the South (urban $22.6 \%$ and rural $24.0 \%$ ) and Mexico City has the lowest prevalence in urban areas.

The overall prevalence of anemia among nonpregnant women of indigenous ancestry was $24.8 \%$ in comparison with $20.4 \%$ in non-indigenous women. For non-pregnant indigenous women, the highest prevalence $(39.9 \%)$ was found in the North and the lowest in the South (Table III).

The crude odds ratio for anemia was 1.51 for the older age category $(95 \% \mathrm{CI} 1.33,1.71), 1.49$ for women with no schooling $(95 \% \mathrm{CI} 1.12,1.98), 1.97$ for the highest category of parity $(95 \% \mathrm{CI} 1.67,2.31), 1.26$ for illiterate mothers $(95 \% \mathrm{CI} 1.06,1.49), 1.52$ for low socioeconomic level $(95 \% \mathrm{CI} 1.34,1.72)$, and 1.29 for indigenous background $(95 \% \mathrm{CI} 1.11,1.51)$ (Table IV).

After adjusting for the effect of cluster sampling and for potential confounders using the logistic regression model, women living in the South and in the North had a greater risk of anemia than those living in Mexico City $(p=0.005)$. Significant risk factors were greater parity $(p<0.0001)$ and having a medium or low socioeconomic level $(p<0.0001)$ (Table V). The logistic mod-

Table I

MeAn, Median ANd 95\% Cl of Hemoglobin (G/DL) In WOMEn 12 to 49 YeARS OLD ACCORDING TO PHYSIOLOGICAL CONDITION BY REGION, AREA, AND NATIONAL LEVEL PARTICIPATING the National Nutrition Survey. Mexico, 1999

\begin{tabular}{|c|c|c|c|c|c|c|c|c|c|c|c|c|c|}
\hline \multirow[b]{2}{*}{ Region/area } & \multicolumn{5}{|c|}{ Pregnant women } & \multicolumn{5}{|c|}{ Non-pregnant women } & \multicolumn{3}{|c|}{ All women } \\
\hline & $\begin{array}{l}\text { Sample } \\
\text { numbe }\end{array}$ & $\begin{array}{l}\text { Expansion* number } \\
\text { (thousands }\end{array}$ & Mean & $95 \% \mathrm{Cl}$ & Median & $\begin{array}{l}\text { Sample } \\
\text { number }\end{array}$ & $\begin{array}{l}\text { Expansion* number } \\
\text { (thousands) }\end{array}$ & Mean & $95 \% \mathrm{Cl}$ & Median & Mean & $95 \% \mathrm{Cl}$ & edian \\
\hline orth & 208 & 160.6 & 11.7 & 1.34 & 11.7 & 5059 & 838.3 & 13.0 & (12.91 & ) 13.1 & 12.9 & (12.86 & ) 13.0 \\
\hline enter & 211 & 277.8 & 11.9 & $(11.67,12.19)$ & 11.9 & 4645 & 014.4 & 13.1 & $(13.08,13.21)$ & 13.3 & 13.1 & $(13.02,13.16)$ & ) 13.3 \\
\hline Mexico City & 59 & 137.6 & 12.3 & $(11.84,12.74)$ & 12.3 & 1538 & 3186.1 & 13.5 & $(13.35,13.56)$ & 13.5 & 13.4 & $(13.30,13.51)$ & ) 13.5 \\
\hline South & 219 & 269.7 & 11.8 & $(11.53,11.99)$ & 11.7 & 5254 & 6492.9 & 13.0 & $(12.89,13.01)$ & ) 13.0 & 12.9 & $(12.84,12.96$ & 13.0 \\
\hline rban & 397 & 592.6 & 11.9 & $11.70,12.09)$ & 11.9 & 10283 & 14372.3 & 13.1 & $(13.10,13.19)$ & 13.3 & 13.1 & $(13.04,13.14)$ & ) 13.2 \\
\hline iral & 300 & 253.0 & 11.9 & $11.65,12.10)$ & 12.0 & 6213 & 5159.5 & 13.0 & $(12.92,13.04)$ & 13.1 & 12.9 & $(12.86,12.99)$ & ) 13.1 \\
\hline ational & 697 & 845.6 & 11.9 & $(11.74,12.04)$ & 12.0 & 16496 & 19531.8 & 13.1 & $(13.06,13.14)$ & 13.2 & 13.1 & $(13.01,13.08)$ & 13.2 \\
\hline
\end{tabular}

* Estimated number using exansion factors without adjusting for women who did not have valid hemoglobin values 
Table II

Prevalence (\%) of anemia* in 12- to 49-Year-old women according to physiological status, area, and region participating the National Nutrition Survey. Mexico, 1999

\begin{tabular}{|c|c|c|c|c|c|c|c|c|c|c|}
\hline \multirow[b]{2}{*}{ Region } & \multicolumn{4}{|c|}{ Urban } & \multicolumn{4}{|c|}{ Rural } & \multicolumn{2}{|r|}{ National } \\
\hline & $\begin{array}{l}\text { Sample } \\
\text { number }\end{array}$ & $\begin{array}{l}\text { Expansion }{ }^{\ddagger} \text { number } \\
\text { (thousands) }\end{array}$ & $\%$ & $95 \% \mathrm{Cl}$ & $\begin{array}{l}\text { Sample } \\
\text { number }\end{array}$ & $\begin{array}{l}\text { Expansion } \text { number }^{\text {(thousands) }}\end{array}$ & $\%$ & $95 \% \mathrm{Cl}$ & $\%$ & $95 \% \mathrm{Cl}$ \\
\hline \multicolumn{11}{|l|}{ Pregnant women } \\
\hline N orth & 124 & 132.3 & 32.3 & $(21.96,42.60)$ & 84 & $-\S$ & - & - & - & - \\
\hline Center & 111 & 185.9 & 27.5 & $(16.77,38.28)$ & 100 & 91.9 & 28.1 & $(16.62,39.55)$ & 27.7 & $(19.90,35.52)$ \\
\hline Mexico City & 53 & 134.3 & 20.1 & $(9.05,31.10)$ & 6 & - & - & - & - & - \\
\hline South & 109 & 140.2 & 30.8 & $(22.16,39.39)$ & 110 & 129.5 & 28.9 & $(19.13,38.76)$ & 29.9 & $(23.57,36.22)$ \\
\hline Total & 397 & 592.6 & 27.7 & $(22.44,32.89)$ & 300 & 253.0 & 28.0 & $(21.34,34.62)$ & 27.8 & $(23.69,31.82)$ \\
\hline \multicolumn{11}{|c|}{ Non-pregnant women } \\
\hline North & 3170 & 3215.5 & 20.5 & $(18.47,22.62)$ & 1889 & 622.8 & 22.8 & $(19.78,25.80)$ & 20.9 & $(19.14,22.68)$ \\
\hline Center & 2624 & 4204.7 & 20.6 & $(18.50,22.70)$ & 2021 & 1809.7 & 20.5 & $(18.52,22.58)$ & 20.6 & $(19.05,22.12)$ \\
\hline Mexico City & 1460 & 3149.1 & 16.3 & $(13.82,18.71)$ & 78 & - & - & - & - & - \\
\hline South & 3029 & 3803.1 & 22.6 & $(20.72,24.49)$ & 2225 & 2689.8 & 24.0 & $(21.41,26.50)$ & 23.2 & $(21.64,24.69)$ \\
\hline Total & 10283 & 14372.3 & 20.2 & $(19.11,21.22)$ & 6213 & 5159.5 & 22.6 & $(21.05,24.19)$ & 20.8 & $(19.95,21.68)$ \\
\hline \multicolumn{11}{|l|}{ All women } \\
\hline North & 3294 & 3347.8 & 21.0 & $(18.97,23.05)$ & 1973 & 651.2 & 22.9 & $(19.82,26.06)$ & 21.3 & $(19.58,23.07)$ \\
\hline Center & 2735 & 4390.6 & 20.9 & $(18.81,22.97)$ & 2121 & 1901.6 & 20.9 & $(18.79,23.03)$ & 20.9 & $(19.37,22.43)$ \\
\hline Mexico City & 1513 & 3283.3 & 16.4 & $(14.05,18.79)$ & 84 & - & - & - & 16.5 & $(14.16,18.85)$ \\
\hline South & 3138 & 3943.3 & 22.9 & $(21.04,24.76)$ & 2335 & 2819.3 & 24.2 & $(21.56,26.81)$ & 23.4 & $(21.89,24.97)$ \\
\hline Total & 10680 & 14964.9 & 20.5 & $(19.43,21.50)$ & 6513 & 5412.5 & 22.9 & $(21.25,24.50)$ & 21.1 & $(20.24,21.97)$ \\
\hline
\end{tabular}

Table III

Prevalence (\%) of anemia* in non-Pregnant women in a national Probabilistic sample, BY REGION AND INDIGENOUS BACKGROUND

\begin{tabular}{|c|c|c|c|c|c|c|c|c|}
\hline \multirow[t]{2}{*}{ Region } & \multicolumn{4}{|c|}{ Indigenous } & \multicolumn{4}{|c|}{ Non-indigenous } \\
\hline & $\begin{array}{c}\mathrm{N} \\
\text { (Sample) }\end{array}$ & $\begin{array}{c}\mathrm{N} \\
\text { (Expanded) })^{\ddagger}\end{array}$ & $\%$ & $95 \% \mathrm{Cl}$ & $\begin{array}{c}\mathrm{N} \\
\text { (Sample) }\end{array}$ & $\begin{array}{c}n \\
\text { (Expanded) })^{\ddagger}\end{array}$ & $\%$ & $95 \% \mathrm{Cl}$ \\
\hline North & 163 & 74.2 & 39.9 & $(29.03,50.78)$ & 4896 & 3764.2 & 20.5 & $(18.76,22.31)$ \\
\hline Center & 179 & 227.8 & 27.0 & $(20.54,33.50)$ & 4466 & 5786.6 & 20.3 & $(18.74,21.92)$ \\
\hline$\overline{\text { Mexico City }}$ & 40 & - & - & - & 1498 & 3091.6 & 16.2 & $(13.74,18.73)$ \\
\hline South & 1097 & 1298.0 & 23.8 & $(20.76,26.92)$ & 4157 & 5195.0 & 23.0 & $(21.27,24.72)$ \\
\hline$\overline{N \text { ational }}$ & 1479 & 1694.5 & 24.8 & $(22.15,27.43)$ & 15017 & 17837.3 & 20.4 & $(19.53,21.35)$ \\
\hline
\end{tabular}

* Adjusted for altitude: $<12 \mathrm{~g} / \mathrm{dl}$ in non-pregnant women, above sea level

₹ Estimated number using expansion factors without adjusting for women who did not have valid hemoglobin values

$\S \quad$ Not presented due to small sample size

el was originally adjusted for indigenous background, maternal education, employment status and maternal literacy, but none of these variables were statistically significant, and were therefore removed from the model presented in Table V.

\section{Discussion and conclusions}

Our findings documented that anemia in women is a serious public health problem in Mexico, affecting about one fifth of non-pregnant women of reproduc- 
Table IV

Prevalence (\%) and Crude risks for anemia* among non-pregnant women in a national probabilistic sample, BY URBAN OR RURAL AREA, AGE, PARITY, SCHOOLING AND LITERACY, SOCIOECONOMIC INDEX, and indigenous background participating the National Nutrition Survey, México, 1999

\begin{tabular}{|c|c|c|c|c|c|c|}
\hline & $\begin{array}{c}\mathrm{n} \\
\text { (Sample) }\end{array}$ & $\begin{array}{c}n \\
(\text { Expanded })^{\ddagger}\end{array}$ & $\begin{array}{c}\text { Anemia } \\
(\%)\end{array}$ & $\begin{array}{l}\text { Odds ratios } \\
\text { Crude }\end{array}$ & $95 \% \mathrm{Cl}$ & $p$ \\
\hline \multicolumn{7}{|l|}{ Area } \\
\hline Urban & 10114 & 14143.8 & 20.1 & 1.00 & & \\
\hline Rural & 6025 & 5003.6 & 22.5 & 1.16 & $(1.03,1.30)$ & 0.014 \\
\hline \multicolumn{7}{|l|}{ Region } \\
\hline Mexico City & 1526 & 3162.4 & 16.5 & 1.00 & & \\
\hline North & 4966 & 3775.1 & 21.0 & 1.34 & $(1.09,1.65)$ & 0.006 \\
\hline Center & 4494 & 5838.5 & 20.4 & 1.30 & $(1.06,1.59)$ & 0.011 \\
\hline South & 5153 & 6371.5 & 23.1 & 1.53 & $(1.26,1.86)$ & $<0.0001$ \\
\hline \multicolumn{7}{|l|}{ Age (years) } \\
\hline 12 to 18 & 4222 & 4830.9 & 16.9 & 1.00 & & \\
\hline 19 to 35 & 7613 & 9162.3 & 21.2 & 1.32 & $(1.17,1.49)$ & $<0.0001$ \\
\hline 36 to 49 & 4304 & 5154.3 & 23.5 & 1.51 & $(1.33,1.71)$ & $<0.0001$ \\
\hline \multicolumn{7}{|l|}{ Parity (\# children) } \\
\hline 0 & 6253 & 7471.7 & 16.3 & 1.00 & & \\
\hline 1 to 2 & 4200 & 5208.3 & 22.7 & 1.51 & $(1.34,1.71)$ & $<0.0001$ \\
\hline 3 to 5 & 4289 & 4958.8 & 23.3 & 1.57 & $(1.39,1.77)$ & $<0.0001$ \\
\hline$>5$ & 1397 & 1508.5 & 27.6 & 1.97 & $(1.67,2.31)$ & $<0.0001$ \\
\hline
\end{tabular}

Schooling

\begin{tabular}{lrrrrrr} 
Professional & 536 & 842.4 & 16.9 & 1.00 & & \\
\hline N one & 4539 & 5020.7 & 23.2 & 1.49 & $(1.12,1.98)$ & 0.0070 \\
\hline Elementary & 5408 & 5967.3 & 21.1 & 1.32 & $(0.99,1.75)$ & 0.0570 \\
\hline Middle school & 3937 & 4941.8 & 19.7 & 1.21 & $(0.91,1.60)$ & 0.1900 \\
\hline High school & 1663 & s2 306.5 & 18.2 & 1.10 & $(0.82,1.47)$ & 0.5240
\end{tabular}

\begin{tabular}{lrrrrrr}
$\begin{array}{l}\text { Maternal literacy } \\
\text { Literate }\end{array}$ & 14856 & 17655.1 & 20.5 & 1.00 & & \\
\hline Illiterate & 1197 & 1378.4 & 24.4 & 1.26 & $(1.07,1.49)$ & 0.0060 \\
$\begin{array}{l}\text { Occupation } \\
\text { Employed }\end{array}$ & 3700 & 4805.7 & 20.3 & 1.00 & & \\
\hline Unemployed & 12373 & 14253.3 & 21.0 & 1.04 & $(0.94,1.16)$ & 0.4420
\end{tabular}

\begin{tabular}{lllllll}
$\begin{array}{l}\text { Socioeconomic index } \\
\text { High }\end{array}$ & 5751 & 7868.3 & 17.3 & 1.00 & & \\
\hline Medium & 5170 & 5815.9 & 22.1 & 1.36 & $(1.20,1.54)$ & $<0.0001$ \\
\hline Low & 5218 & 5463.2 & 24.2 & 1.52 & $(1.34,1.72)$ & $<0.0001$
\end{tabular}

Indigenous ethnicity

\begin{tabular}{lrrrrrr} 
N on-indigenous & 14686 & 17476.8 & 20.3 & 1.00 & & \\
\hline Indigenous & 1453 & 1670.6 & 24.8 & 1.29 & $(1.11,1.51)$ & 0.0010
\end{tabular}

$*<12 \mathrm{~g} / \mathrm{dl}$ in non-pregnant women (adjusted for altitude above sea level)

₹ Estimated number using expansion factors without adjusting for women who did not have valid hemoglobin values

tive age and over one fourth of pregnant women. The serious functional consequences of this deficiency demand the design and implementation of public iron supplementation and food fortification programs as the most effective strategies to reduce iron-deficiency anemia.

Data presented here show a persistently high prevalence of anemia in Mexico among pregnant and non- 
Table V

\section{LOGISTIC REGRESSION MODEL FOR ANEMIA* CONSIDERING COMPLEX SAMPLING VARIANCE AMONG NON-PREGNANT WOMEN IN A NATIONAL PROBABILISTIC SAMPLE, participating the National Nutrition SurVey. MÉxıCoI, 1999}

\begin{tabular}{lccc}
$\begin{array}{l}\text { Independent variables } \\
\text { Region }\end{array}$ & Odds ratio & $95 \%$ confidence interval & $p$ \\
Mexico City & 1.0 & & \\
\hline N orth & 1.3 & $(1.05,1.59)$ & 0.014 \\
\hline Center & 1.2 & $(0.98,1.46)$ & 0.086 \\
\hline South & 1.3 & $(1.09,1.63)$ & 0.005
\end{tabular}

Parity

\begin{tabular}{llll} 
N one & 1.0 & & \\
\hline $1-2$ children & 1.5 & $(1.36,1.73)$ & $<0.0001$ \\
\hline 3 to 5 children & 1.5 & $(1.37,1.75)$ & $<0.0001$ \\
\hline$>5$ children & 1.8 & $(1.51,2.09)$ & $<0.0001$
\end{tabular}

Socioeconomic index ${ }^{\ddagger}$

\begin{tabular}{llll} 
High & 1.0 & & \\
\hline Medium & 1.3 & $(1.15,1.48)$ & $<0.0001$ \\
\hline Low & 1.4 & $(1.22,1.59)$ & $<0.0001$
\end{tabular}

$*<12 \mathrm{~g} / \mathrm{dL}$ (sea level)

₹ $\mathrm{N}$ ormalized index (factorial analysis)

pregnant women. Furthermore, based on the $1988 \mathrm{Na}-$ tional Nutrition Survey, the prevalence of anemia increased from 15.4 to $20.8 \%$ in women of childbearing age and from 18.2 to $27.8 \%$ in pregnant women, ${ }^{15}$ representing an increment of 35.0 and $52.7 \%$ respectively. Several factors may account for the growing prevalence of anemia. Methodological differences between the two surveys may partially explain these differences. Hemoglobin was measured on site in the NNS-1999 by finger-prick capillary testing using a portable photometer, but was not determined on site in the 1988 survey. Also, venous blood was used in 1988 and capillary blood in 1999. Therefore, results of the two surveys may not be comparable. Transportation and storage of the 1988 samples might have influenced hemoglobin concentration values. Also, hemoglobin concentration in capillary blood may be more variable than in venous blood because inclusion of extracellular fluid would decrease the concentration of components present in the red cell fraction ${ }^{27}$, and the amount of extracellular fluid present in finger-prick samples is likely to be very sensitive to the technician's handling of the patient's finger.
Differences in the prevalence of anemia may also be explained partly by changes in the dietary patterns of the population. For instance, based on the economic difficulties experienced in Mexico during the last ten years, we speculate that recently, diets of a vast section of the population include lower amounts of animal-based foods. Rivera $e^{a}{ }^{28}$ found that the purchase of meat and meat-products decreased in the 14 year period from 1984 to 1998. The lack of public health interventions to prevent and treat iron deficiency may contribute to the increase in the prevalence of anemia. It was not until 1998 that nutritional interventions were implemented to decrease micronutrient deficiencies among poor women in Mexico. Specifically, the Program for Education, Health and Nutrition (Progresa, now called Oportunidades), which distributes fortified foods to low-income pregnant and lactating women, as well as the fortification of wheat and corn flours with iron and other micronutrients and the distribution by the Ministry of Health of multiple micronutrient supplements to pregnant women in predominantly indigenous communities.

The highest prevalence of anemia found in pregnant women should be interpreted cautiously, since it may be due in part to the hemodilution occurring during the last trimester of pregnancy. The cut-off criteria to diagnose anemia is lower for pregnant women in order to correct for overdiagnosis; however, during the first trimester and partially during the second trimester when hemodilution has little effect on the levels of hemoglobin, overcorrection must occur. We did not apply specific cut-off points for each trimester of pregnancy, because we did not have individual information about the length of gestation.

The greatest prevalence of anemia was found in indigenous women living in rural zones. It is well know that indigenous populations are the poorest in Mexico and have the lowest availability of social support resources. $^{29}$

It is puzzling that the prevalence of anemia in the North, considered the most developed area of the country, was comparable to that found in the South, which is considered the least developed. This phenomenon was also observed in the 1988 survey and needs further research.

The prevalence of anemia in Mexico is lower than that observed in other developing countries where it is approximately $44.0 \%$ in non-pregnant women and $56.0 \%$ in pregnant women, and higher than that reported for developed countries, where it is approximately $12.0 \%$ in non-pregnant women and $18.0 \%$ in pregnant women. ${ }^{30}$ However, other countries with comparable economic development such as Chile and Costa Rica 
have achieved a prevalence similar to that of developed countries. ${ }^{30}$ Such an achievement was reached by sustained nutritional interventions, resembling those that must be undertaken in Mexico in order to reduce the prevalence of anemia.

This study identified some risk factors associated with anemia in women such as older age, multiparity, ${ }^{31,32}$ lower socioeconomic status, indigenous background and being a resident of rural areas. Most of these factors are closely related to both poverty and anemia, as has been reported in other studies. ${ }^{14,31-34}$

The increased prevalence of anemia associated with parity could be due to a progressive depletion of nutritional stores during pregnancy, that has been documented in women of other developing countries. ${ }^{34-36}$

Additional variables not evaluated in this analysis should be taken into account, such as dietary factors including intake of foods with lower iron biodisponibility and cigarette smoking.

This study provides information on the prevalence of anemia among women of childbearing age in a nationwide representative sample that included urban and rural areas of the four regions of Mexico. Anemia in women of childbearing age is a serious public health problem in Mexico, affecting not only populations living under harsh conditions but also groups with higher socioeconomic status. Its prevalence has shown increasing trends over the past 10 years, although methodologies differ between surveys and may not be comparable. The problem should be approached through aggressive interventions targeted at groups at risk in order to rapidly reduce the prevalence of anemia, thus limiting its negative short- and long-term effects on other health outcomes.

As mentioned before, several interventions aimed at reducing micronutrient deficiencies were implemented shortly after the 1999-NNS. It is therefore expected that anemia prevalence may have been reduced. Some but not all of these programs are currently being evaluated and it is likely that the next $\mathrm{Na}-$ tional Nutrition Survey will be able to assess changes in the prevalence of anemia in the population after the implementation of these interventions. In the meanwhile, several strategies may be launched simultaneously, such as the fortification of foods other than wheat and corn flours and in addition existing programs should be strengthened.

\section{Acknowledgements}

We would like to acknowledge Dra. Teresa GonzálezCossío for her comments and suggestions to our manuscript.

\section{References}

1.Yip R. Iron fortification: Prevention of iron deficiency for developing countries. In: Forum on Iron Fortification. Institute of Food Technologists. A nnual Meeting. Atlanta (GA): June 1998.

2. Black AK, A llen LH, Pelto GH, De Mata MP, Chávez A. Iron, vitamin B12 and folate status in Mexico:Associated factors in men and women and during pregnancy and lactation.J N utr 1994;124:1179-1188.

3. Freire W B. La anemia por deficiencia de hierro: estrategias de la O PS/ O MS para combatirla. Salud Publica Mex 1998;40:199-205.

4.Van den Broek N R, Letsky EA. Etiology of anemia in pregnancy in south Malawi.Am J C lin N utr 2000;72(Suppl):247S-256S.

5. Bundy DAP,W ong MS, Lewis LL, Horton J. Control of geohelminths by delivery of targeted chemotherapy through schools. Trans R Soc Trop Med Hyg 1990;84:115-120.

6. Simmons W K. Control de la deficiencia de hierro en El Caribe de habla inglesa. Bol 0 ficina Sanit Panam 1994;117(6):538-546.

7. Stoltzfus RJ, D reyfuss ML, Jorgenson T, C hwaya-Hababu M, A lbonico

M. Control de la helmintiasis como estrategia para prevenir la deficiencia de hierro. En: D eficiencia de hierro. Desnutrición oculta en A mérica Latina. C ESN I. Centro Asociado de la Facultad de Medicina del Ecuador. 1997:259-278.

8. Rawlins SC, James 0 , and Gibbs W N . C urrent patterns of uncinariasis and its relationship to iron deficiency anemia.W est Indian Med J

1984;33(4):258-263.

9. International N utritional Anemia Consultive Group. Guidelines for the control of maternal nutritional anemia.A report of the International N utritional Anemia Consultive Group. Ciudad: IN AG, 1999.

10. Brabin BJ, Hakimi M, Pelletier D. An analysis of anemia and pregnancy-related maternal mortality. J N utr 2001;131(N 0. 2S-II): 604S-615S.

11. Hadary CJ, Haas JD. Hemoglobin correction factors for estimating the prevalence of iron deficiency anemia in pregnant women residing at high altitudes in Bolivia. Pan Am J Public Health 1999;6(6):392-399.

12. lyengar GV, N air PP. G lobal outlook on nutrition and the environment: Meeting the challenges of the next millennium. Sci Total Environ 2000;249(1-3):331-346.

13. O 'D onell A, Chevallier MC. N utrición en el ciclo reproductivo: embarazo y lactancia. Boletín C ESN I, Buenos Aires, A rgentina: agosto 1999:1-20.

14. Rush D. N utrition and maternal mortality in developing world. Am J Clin N utr 2000;72 (Suppl):212S-240S.

15. Martínez H, G onzález-C ossío T, Flores M, Rivera DJ, Lezana MA, Sepúlveda AJ.Anemia en edad reproductiva. Resultados de una encuesta probabilística nacional. Salud Publica Mex 1995;37:108-119.

16. Rivera-D ommarco J, Shamah Levy T,Villalpando-Hernández S, González-C ossío T, Hernández-Prado B, Sepúlveda J, ed. Encuesta $\mathrm{N}$ acional de $\mathrm{N}$ utrición 1999. Estado $\mathrm{N}$ utricio de $\mathrm{N}$ iños y Mujeres en México. Cuernavaca, Morelos, México: Instituto N acional de Salud Pública; 2001.

17. W orld Health 0 rganization. The prevalence of anemia in women:A tabulation of available information. 2nd edition. Geneva:W HO, 1992.

18. Cohen JH, Hass JD. Hemoglobin correction factors for estimating the prevalence of iron deficiency anemia in pregnant women residing at high altitudes in Bolivia. Pan Am J Public Health 1999;6(6):392-399.

19. Instituto $\mathrm{N}$ acional de Estadística, Geografía e Informática. Conteo de población y vivienda 1995: Resultados definitivos:Tabulados Básicos. México, DF: IN EGI, 1996.

20. Johns W L, Lewis SM. Tamizaje de la anemia en atención primaria de salud mediante hemoglobinometría en una comunidad tropical. Bol 0 ficina Sanit Panam 1992;112(3):214-221. 
21. Alok B, Howarth EB, N evin SS. Dietary intakes and socioeconomic factors are associated with the hemoglobin concentration of Bangladeshi women.J N utr 2001;131:758-764.

22. Idrus J, Endang L, A chadi, G alloway R, D yanto A, Zazri A et al. Reaching young Indonesian women through marriage registries: $A n$ innovative approach for anemia control J N utr 2000;130:456.

23. Suitor CJW, Gardner J,W illett W C.A comparison of food frequency and diet recall methods in studies of nutrient intake of low-income women. J Am Diet Assoc 1989;89:1786-1794.

24.Johnson-Spear MA,Yip R. Hemoglobin difference between black and white women with comparable iron status: Justification for race-specific anemia criteria. Am J C lin N utr 1994;60:117-121.

25.Jackson RT. Separate Hb standards for blacks and whites:A critical review of the case for separate and unequal $\mathrm{Hb}$ standards. Med Hypotheses 1990;32:181-189.

26. Pehrsson PR, Moser-Veillon PB, Sims LS, Suitor CW, Russek-C ohen E. Postpartum iron status in nonlactating participants and nonparticipants in the Special Supplemental N utrition Program for W omen, Infants, and Children. Am J C lin N utr 2001;73:86-92.

27. Morris SS, Ruel MT, C ohen RJ, D ewey KG, De la Briere B, Hassan $M N$. Precision, accuracy, and reliability of hemoglobin assessment with use of capillary blood. Am J Clin N utr 1999;69:1243-1248.

28. Rivera J, Barquera S, C ampirano F, C ampos I, Safdie M,Tovar V. Epidemiological and nutritional transition in Mexico: Rapid increase of non-communicable chronic diseases and obesity. Public Health $\mathrm{N}$ utr 2002;5(1)113-122.

29. Rivera JA, Monterrubio EA, G onzález-C ossío T, García-Feregrino R, García-G uerra A, Sepúlveda-A mor J. N utritional status of indigenous children younger than five years of age in Mexico: Results of a $\mathrm{N}$ ational Probabilistic Survey Salud Publica Mex 2003;45 suppl 4: s466-\$476. 30. United $N$ ations Administrative Committee on Coordination SubCommittee on N utrition ( $A C C / S C N$ ), in collaboration with International Food Policy Research Institute. Geneva:ACC/SC N , 2000. The world nutrition situation. N utrition throughout the life cycle. 31. Frith-Terhune,AL, Cogswell ME, Kettel-Khan L,W ill JC, Ramakrishnan U. Iron deficiency anemia: Higher prevalence in Mexican American than in non-Hispanic white females in the third $\mathrm{N}$ ational Health and N utrition Examination Survey, 1988-1994. Am J C lin N utr 2000;72:963-968.

32. Zavaleta N , C aulfield LE, García T. C hanges in iron status during pregnancy in Peruvian women receiving prenatal iron and folic acid supplements with or without zinc. Am J C lin N utr, 2000;71(4):956-961. 33. Becerra C, G onzález GF,Villena A, D e la C ruz D, Florián A. Prevalencia de anemia en gestantes. Hospital Regional de Pucallpa, Perú. Rev Panam Salud Publica 1998;3(5):285-291.

34. Diallo MS, Diallo TS, Diallo FB, D iallo Y, C amara AY, 0 nivogui $G$ et al. Anemia and pregnancy: Epidemiologic, clinical and prognostic study at the university clinic of the Ignace Deen Hospital, Conakry (Guinée). Rev Fr Gynecol O bstet 1995;90:138-141.

35.Villar J, Rivera J. N utritional supplementation during two consecutive pregnancies and the interim lactation period: Effect on birth weight. Pediatrics 1988:81:51-57.

36. Brunvand L, Henriksen C, Larsson M, Sandberg AS. Iron deficiency among pregnant Pakistanis in N orway and the content of phytic acid in their diet. Acta 0 bstet Gynecol Scand 1995;74: 520-525. 